\title{
COVID-19 Pandemic: Expanding the Public-private Partnerships Practice in the "Epinomic" Policy
}

\author{
Vaslavskiy Y. \\ Moscow State Institute of International Relations (MGIMO University), Moscow, Russian Federation \\ *Corresponding author.Email: vaslavsky@yandex.ru
}

\begin{abstract}
The emergency conditions caused by the coronavirus pandemic in 2020 made the national governments the last resort, which was forced to bear all the financial costs associated with the lockdown in the national economy, with social support of the population and fiscal and monetary help to private firms which business was blocked. Lockdowns, publicly declared in countries around the world to stop the exponential growth of coronavirus-infected patients, have brought unprecedented losses in both human lives and national welfare. As a result, the coronavirus pandemic left two fundamental priorities for the state: (1) to stabilize the epidemiological situation in the country and (2) to reopen the economy in time after the lockdown. On this basis, the term "epinomics" was introduced, which assumes the primary public task to ensure the life and health of citizens, and only under this condition allows the possibility of economic recovery. In this case, the expansion of the practice of implementing public infrastructure projects on the basis of public-private partnership realizes the essence of the state's epinomic strategy. Moreover, in the post-COVID-19 future, infrastructure projects can become an effective form of implementation of the UN "human-first" model, since they allow solving the immediate problems of ordinary citizens mostly affected in 2020. It is about the growth of employment, the provision of workforce wages, development of socially significant infrastructure, which contribution to the economic revival of countries can hardly be overestimated. At the same time, the government through public-private partnership gets the opportunity to directly broadcast to society the results of the effectiveness of its epinomic strategy in stabilizing the epidemiological situation and reopening the economy after the lockdown.
\end{abstract}

Keywords: epidemiology and Economics, "Human-first" Model, "Failures" of the State

\section{INTRODUCTION}

Historically, there has been little connection between the studies of epidemiology and economics, as contemporary disease outbreaks have not had such disastrous economic consequences. However, the COVID-19 pandemic changed everything, since in most countries of the world public authorities were forced to introduce regimes of economic and social lockdowns as the only means to prevent the exponential growth of coronavirus infection. Protecting the health of citizens has become a real priority goal of national governments, subjugating all economic preferences. This allowed the experts of the Boston Consulting Group to link them in a single term of "epinomics". In these conditions, the issue of adaptation and improvement of the Virus-Monitoring System becomes the most important. To get better, faster information about changes in the virus's local status means the possibility to reflect policy decisions (such as accompanying a choice to open schools with a surge in testing of students) in economics. In addition to the local nature of these decisions, there needs to be a central capability to learn from the distributed experiences and use that knowledge to adapt the distributed models. This would not shorten the COVID-19 pandemic fighting, but it might allow the governments to both save lives and to reopen the economy after the lockdown.

Under the full reboot model, the government waits until new COVID-19 cases are at zero and then restarts social and economic activity with minimal restrictive measures but with limited (or no) international travel. This strategy requires a set of conditions that may not be feasible for most countries, including tight border controls, high volumes of testing and contact tracing, and the ability to enforce an initial lengthy lockdown period.

The second approach allows for the widespread restarting of social and economic activity but continued strict isolation for vulnerable populations such as the elderly. Such an approach may not be feasible in many countries, given the large numbers of people who would need to remain in isolation until a vaccine or cure is available. However, it may be the right strategy for restarting activity in the near term for low-income countries that are unable to rapidly build up health care and testing capacity without international assistance.

The third approach is likely to be the most widely adopted. Under this graduated model, governments lift restrictions in a deliberate, phased, and incremental manner based on the progression of the disease, the readiness of the public 
health system, and the preparedness of the public. This approach is in varying stages of introduction around the world, with countries in Asia and Europe leading the way. Today local government officials and public health decision-makers will have to make decisions that balance the disease trajectory with policy choices - and understand the implications of these tradeoffs. In these conditions, the partnership of national states and private investors in the implementation of socially significant projects becomes not only possible, but even more necessary than before COVID-19. Besides, in crisis the importance of socially significant projects, especially in infrastructure, increases greatly due to reducing the period of economic recession. Under COVID-19, such importance of PPPs in public infrastructure should be interpreted in the context of the need to form and expand the organizational structures of partnerships (cooperation, cooperation) between the state and private business, which potential is huge and can be successfully used to unlock the economic "lockdown" at the national level. Under the current conditions, it would be very important to theoretically rethink the reasons that impeded the widespread practice of PPPs development before COVID-19, as well as the conditions that should be created for the rapid implementation of the diverse forms of such a partnership in the post-Covid-19 recovery phase [Baxter, (2020)].

\section{METHODOLOGY}

The modern world is in transition that implies progress with the risk of backsliding into successive waves of coronavirus disease, W-shaped recoveries, and further economic and human devastation [Gjaja, et al., (2020)]. According to BCG the process of fighting the COVID-19 pandemic could be divided into three phases: flatten, fight, and future. In the flatten phase countries lock down to flatten the virus's exponential growth curve. In the fight phase national governments attempt to restart their economies while maintaining a low rate of infection, while still running the risk of having to implement further lockdowns. The future phase will begin only after a vaccine or highly effective treatment being developed and deployed [BCG. (2020)].

In passing each of the above phases the national governments are making several policy alternatives comparing tradeoffs between health outcomes and economic and societal costs. In other words, any public strategy combines the two main functions of the state, predetermined by the COVID-19 shock: (1) epidemiological situation stabilising and (2) economic reopening. Based on these considerations, BCG experts called epinomic any public strategies in the fighting COVID-19 pandemic. However, depending on the specific forms of their embodiment, all the epinomic strategies can be reduced to three modifications: (1) crush and contain, (2) flatten and fight, and (3) sustain and support (Fig. 1). The uncertainties about which strategy to pursue are manifold still learning the health, economic, and social costs of each. But the epinomics of flatten and fight are inherently expensive. This strategy will test the resolve of governments and society as both seek balance in health and economic outcomes.

\begin{tabular}{|c|c|c|c|}
\hline & & MOST COMMON APPROACH -. & \\
\hline & Crush and contain & Flatten and fight & Sustain and support \\
\hline OBJECTIVE & $\begin{array}{l}\text { Full containment to reduce the number } \\
\text { of local coronavirus cases to close to } \\
\text { zero through rapid, stringent lockdowns, } \\
\text { combined with aggressive testing, tracking, } \\
\text { contact tracing, quarantining, and isolating }\end{array}$ & $\begin{array}{l}\text { Attempted containment with strong } \\
\text { interventions to decrease the number of } \\
\text { coronavirus cases and avoid overwhelming } \\
\text { the health care system's capacity }\end{array}$ & $\begin{array}{l}\text { Open containment with moderate } \\
\text { interventions and primary reliance on } \\
\text { voluntary restraint to limit the number of } \\
\text { coronavirus cases until herd immunity is } \\
\text { achieved or a vaccine or cure is developed }\end{array}$ \\
\hline $\begin{array}{l}\text { IMPLICATIONS } \\
\text { FOR RESTART }\end{array}$ & $\begin{array}{l}\text { Opening the economy in a walled } \\
\text { society, focusing on strict border controls } \\
\text { and testing to keep the number of new } \\
\text { cases to an absolute minimum and } \\
\text { restore economic vitality }\end{array}$ & $\begin{array}{l}\text { Progressively lifting restrictions } \\
\text { and reopening the economy without } \\
\text { surpassing the health care system's limits }\end{array}$ & $\begin{array}{l}\text { Prolonged quarantining of the } \\
\text { vulnerable population, while the less } \\
\text { vulnerable pursue economic activities } \\
\text { with few constraints but continued } \\
\text { health precautions }\end{array}$ \\
\hline PREREQUISITES & $\begin{array}{l}\text { - Early, stringent interventions and the } \\
\text { acceptance of prolonged lockdowns, } \\
\text { when necessary } \\
\text { - Strict border control } \\
\text { - High volumes of testing and contact } \\
\text { tracing relative to the number of cases }\end{array}$ & $\begin{array}{l}\text { - Resources to expand the health care } \\
\text { system's capacity } \\
\text { - Ability to increase coronavirus monitoring } \\
\text { (testing, tracking, and contact tracing) } \\
\text { - Adherence to safety protocols during } \\
\text { the reopening }\end{array}$ & $\begin{array}{l}\text { - Ability to isolate and support the } \\
\text { socioeconomic well-being of the } \\
\text { vulnerable } \\
\text { - High trust in government translating } \\
\text { into high compliance levels } \\
\text { - Favorable demographics }\end{array}$ \\
\hline EXAMPLES & $\begin{array}{l}\text { China, New Zealand, South Korea, } \\
\text { and Taiwan }\end{array}$ & $\begin{array}{l}\text { Brazil, Germany, Italy, Nigeria, the UK, } \\
\text { and the US }\end{array}$ & Sweden \\
\hline
\end{tabular}

Figure 1 Three specific epinomic strategies of national governments in beating the coronavirus Source: The World Bank, Oxford COVID-19 Government Tracker, Wordometer, BCG analysis

The emergence of new terms, such as epinomics, denoting public strategies of the state, the theoretical foundations of which have already been created and approaches to interpretations are distinguished by serious conservatism, indicates that COVID-19 has raised new questions about the activity of the state. The first and most significant of 
them is related to the fact why the states of the countries of the world could not timely stop the exponential growth of the disease fatal to humans. It fits into the mainstream of numerous studies on the inefficiency of the state. Some researchers see the reasons for this in the peculiarities of national economic systems and national communities (Pigou, 1924; Musgrave, 1959; Bator, 1960). Other theorists associate the ineffectiveness of the state with its inadequate performance of the "redistributive function". In this regard, R. Musgrave (1959) identified the three key functions of the state, which determine the share of a country's GDP redistributed to the budgets of national governments. These are the following functions of the state: (1) allocation of resources; (2) economic stabilization (subject to cost-effectiveness) and (3) (fair) redistribution of income. Following the logic of $\mathrm{R}$. Musgrave, the reasons for the inefficiency of the state should be sought in the distribution of budget funds between three groups of budget expenditures in accordance with the key functions of the state. (Ritter, 1996; Tanzi, and Schuknecht, 2000).

The coronavirus pandemic has brought this problem to a new level, highlighting those areas in which the state has shown its complete social unsuitability. As a result, National Societies found themselves in a situation of social and economic lockdowns, which led to an unprecedented crisis in human history. By April 2020, the unprecedented scale of the economic recession, called the "Great lockdown", became apparent. As a result of the COVID19 pandemic, the fall in global GDP in 2020-2021 (Fig. 2) tentatively estimated at $\$ 9$ trillion, which is equivalent to the GDP of Japan and Germany combined. The global economy will suffer such losses if the coronavirus infection is defeated in the second half of 2020. Otherwise, the global GDP could drop by an additional 3\% in 2020. If the COVID-19 pandemic persists in 2021, the global economy will lose another $8 \%$ of GDP compared to the IMF baseline scenario in April 2020. In recent years, a focus on rising healthcare costs, especially in mature economies, has dominated the policy debate, whereas health as an investment in our societies has largely been ignored. The pandemic is an unwelcome reminder of just how much health matters for individuals, society, and the global economy.

(global real GDP level, index)

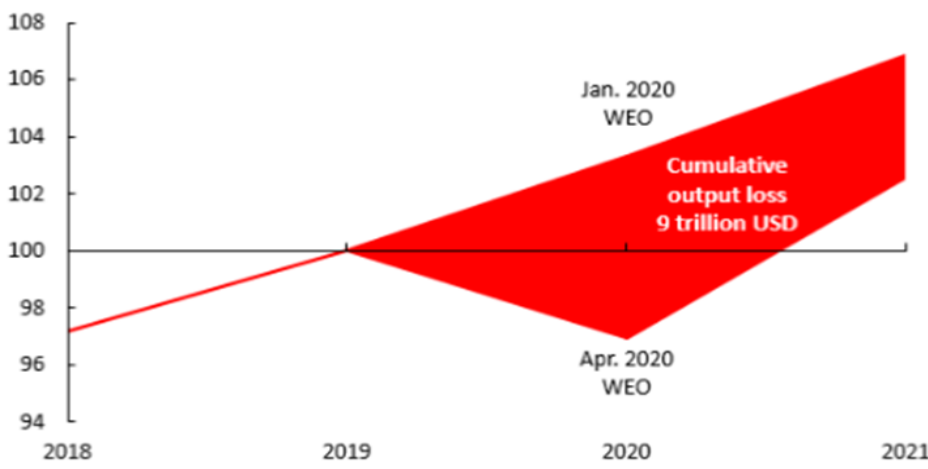

Figure 2 The dynamics of global GDP in the conditions of "Great Self-isolation" in 2020 and of global financial crisis of 2018 2021

Source: IMF(2020) World Economic Outlook April 14

The experts of the Mckinsey Global Institute have analyzed almost 200 countries over two decades to 2040 to identify the different challenges and opportunities facing each, and aggregated findings at regional, income archetype, and global levels to provide a synthesis. [Mckinsey Global Institute (2020)]. Thus, better health could add \$12 trillion to global GDP in 2040, an 8 percent boost that translates into 0.4 percent faster growth every year. About half of these annual economic benefits come from a larger and healthier workforce. The remainder come from expanding the capacity of older people, people with disabilities, and informal caregivers to work as well as from productivity gains as the burden of chronic health conditions is reduced. In other words, the epinomic strategy of states is a long-term phenomenon. In the postCOVID-19 reality the only once-in-a-generation opportunity should be connected with the urgent necessity to rethink the role of health in the future human prosperity. According to Mckinsey Global Institute, the economic and welfare benefits far exceed the implementation costs of achieving this level of health improvement, delivering a GDP uplift of \$2 to \$4 for each \$1 invested over 20 years. This approach includes, among others, moving beyond basic compliance on core labor and human rights standards increase inclusivity, diversity and opportunity for communities and prioritize local recruitment; and using these project platforms to drive local economic development and capacity building, and more broadly improve the quality of life in the surrounding community and region. If it is about the uncertainty, then it is the uncertainty surrounding the COVID-19 and its associated health risks has caused many individuals, households, and businesses to opt out of normal activity. Eliminating that uncertainty is essential to restart growth, and to return trust 
of the households, which is largely predetermined by the development of socially significant infrastructure (Fig. 3). Despite glaring gaps and understood importance of shoring up backbone systems, infrastructure investment actually declined as a share of GDP in 11 of the G20 economies since the global financial crisis of 2008-2009. It was about the European Union, the United States, Russia, and Mexico. By contrast, Canada, Turkey, and South Africa increased investment. If the current trajectory of underinvestment continues, the globe will fall short by roughly 11 percent, or US $\$ 350$ billion a year. The size of the gap triples if the additional investment required to meet the new UN Sustainable Development Goals is included. So it becomes therefore critical to get finance flowing into urgently needed projects.
A great deal of attention has focused on connecting institutional investors with projects that need their capital as well as creating an expanded role for public-private partnerships. But the vast majority of infrastructure will likely continue to be financed by the public and corporate sectors. Even in the face of fiscal concerns, there is substantial scope to increase public infrastructure investment. Governments can increase funding streams by raising user charges, capturing property value, or selling existing assets and recycling the proceeds for new infrastructure. In addition, public accounting standards could be brought in line with corporate accounting so infrastructure assets are depreciated over their life cycle rather than immediately adding to deficits during construction. This change could reduce pro-cyclical public investment behavior.

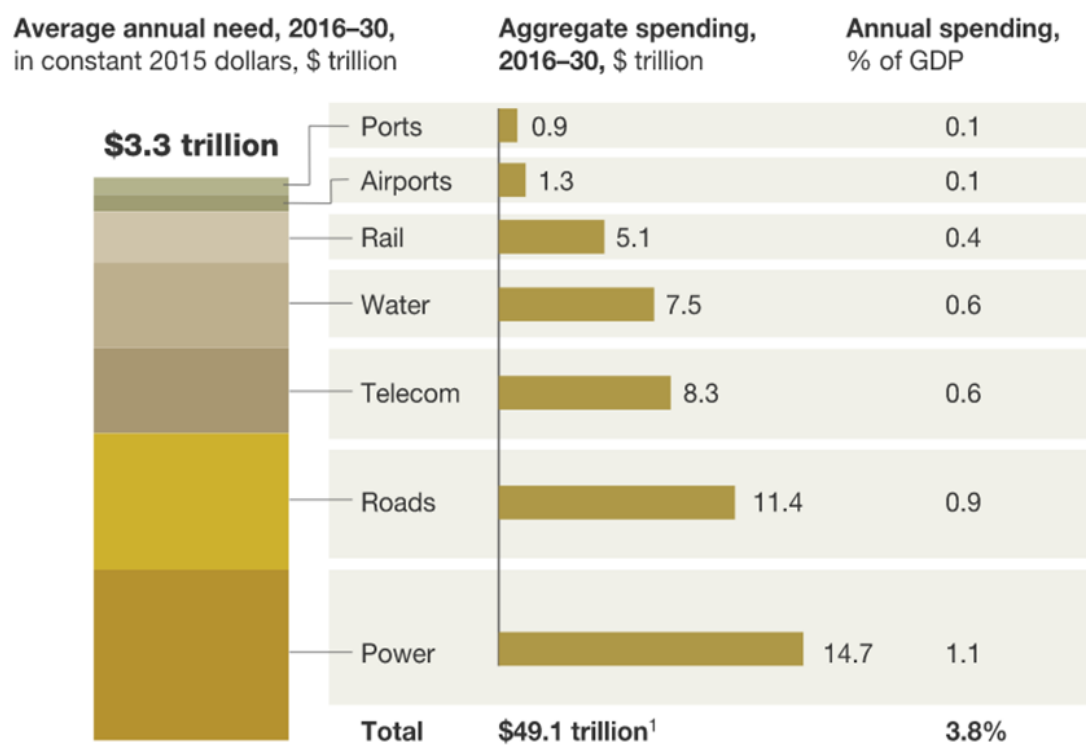

Figure 3 The dynamics of the global needs to invest in economic infrastructure for the period of 2016-2030 Source: McKinsey Global Institute (2013). Infrastructure productivity: How to save US\$1 trillion a year. McKinsey \& Company.

Note: The estimate of total demand is lower than the US\$57 trillion projection in previous MGI research. It has been adjusted for the following reasons: the projection covers a 15-year period (2016-2030) rather than an a 18-year period (2013-2030); water numbers have been reduced by $40 \%$, as Global Water Intelligence adjusted its water capital-expenditure definition to exclude equipment spending; base-year prices have been revised from 2010 to 2015; and GDP growth forecasts have been revised downward by IHS.

Corporate finance makes up about three-quarters of private finance. Unleashing investment in privatized sectors requires regulatory certainty and the ability to charge prices that produce an acceptable risk-adjusted return, as well as enablers like spectrum or land access, permits, and approvals. Beyond ramping up finance, there is even bigger potential in making infrastructure spending more efficient and effective. Only improving project selection, delivery, and management of existing assets could translate into 40 percent savings. Virtually every location needs to build expertise and establishing the right organizational structures for developing critical skills and sharing best practices. This effort can pay remarkable dividends, since infrastructure influences the quality of life for citizens everywhere and paves the way to productivity growth and competitiveness.

\section{RESULTS AND DISCUSSION}

A true "black swan" event like the current coronavirus crisis has revealed how national governments have undermined the importance of resilience in their pursuit of rapid growth at any cost. But COVID-19 shock but the shock showed that it could cause crises in several spheres of the society at the same time and predetermine the priority of the catastrophes and predetermine the priority of the catastrophes catalyzed. As has happened today, 
health problems have come to the fore, dominating the issue of reopening the economy. In these conditions, the state is forced to make economic decisions taking into account the priorities of the public sphere of interest. In this regard, infrastructure projects implemented with the participation of the state and private business acquire special significance, since they relate to the sphere of public goods and benefit the entire society. Under the COVID-19 crisis the importance of the growth of sustainable public infrastructure increases greatly because of its ability to reopen the national and the global economy as soon as coronavirus pandemic ends. Capital-intensive, long-term infrastructure PPP-projects could largely provide an infrastructure breakthrough as the driver of inclusive development of the countries after the COVID19. That is why it is very important to safeguard the necessary amount of capital flow into the PPP infrastructure projects. For example, bridging this gap over a five-year period will involve expenditure totalling approximately $9 \%$ of the EBRD region's GDP in each of these five years. The cost of catching up with the levels expected on the basis of the experiences of advanced comparator economies accounts for $52 \%$ of that total, while improving infrastructure to safeguard postcoronavirus economic reopening accounts for $15 \%$. The remaining $34 \%$ relates to replacement and maintenance requirements over that same time period. According to the World Bank (2017), only to maintain the current level of global GDP, national governments need to spend at least $3.5 \%$ of global GDP (\$3.2 trillion) per year on infrastructure, which together will total $\$ 57$ trillion from 2015 to 2030

Before coronavirus crisis the minimum need for infrastructure investments to support economic growth was $3.5 \%$ of world GDP or $\$ 57$ trillion until 2030 (\$ 3.2 trillion per year). However, in most countries of the world, infrastructure is underfunded by $20-40 \%$. Public investment makes up about $65 \%$, but the possibilities for their further growth are limited by high debt burden and a deficit of state budgets. And today it is necessary to take into account the negative trends associated with an absolute reduction in the growth rate of global GDP due to COVID-19 and a significant increase of the budgets' deficit of national states. The role of private investment, which accounts for $35 \%$ of infrastructure investments, is significantly increasing. Governments of different countries are developing incentives to attract investors and find a reasonable balance between risk and profitability of infrastructure projects. The solution of the problem of large-scale construction and reorganization of the public infrastructure in the country in the post-coronavirus future is possible only within the framework of complementary long-term financing of a system, including the resources of the power structures, institutional and private investors. In other words, subject to consolidation of budget funds, the state should change the structure of the financial market institutionalizing the emergence of debt financing segment oriented on public infrastructure PPP projects financing [Vaslavskaya, (2019)].

As a result the strong economic recovery will benefit everyone if it depends on improved social safety nets and adequate forms of PPPs organization [Pranov, et al., (2019)]. In this case, it is necessary to be aware of serious financial problems that can only be solved on the basis of broad-based fiscal partnership. This includes mixed public-private investment in health care, infrastructure, and climate change [IMF. (2020)]

So the numerous experts concluded that PPP projects in any field, especially in infrastructure, should either be very well prepared by the state, or they will not be effective. Moreover, only in the first case the technology of attracting private investment to implement capitalintensive long-term projects will work. But after the COVID-19 the state could be not in a position to provide full budget financing. It turns out that the conditions dictated by the state depend on whether there will be a quality infrastructure after COVID-19 and whether it will have a positive economic effect. National states associate the post-Great Lockdown future with bringing forward rather than the postponement or cancellation of projects to support employment and economic growth. But for this it is necessary to eliminate the consequences of the negative impact that the current economic crisis will most likely affect PPPs. It is about (1) the additional costs for all PPP projects, particularly those that are operational, mostly due to disinfection of equipment and facilities, and workforce shortages; (2) the decreasing revenue of user-funded PPP projects, particularly transportation and energy projects, due to the much-reduced demand; (3) specific challenges to projects that are in the construction phase, such as construction delays and supply chain disruption.

Estimates confirm that there is substantial scope for improving public investment efficiency in most countries [Baum, et al. (2020)]. In Figure 4 there are presented the estimations of the investment efficiency for up to 164 countries (using various efficiency score estimation methods) as well as the results. The estimated median efficiency gap is large because over one-third of resources are lost in the public investment process. The gap ranges between 33 percent for the data envelopment analysis estimation and 43 percent for the stochastic frontier analysis (adjusted for skewness), with wide variation across countries around this overall range. 


\section{$\times$ Average $\circ$ Outlier value}
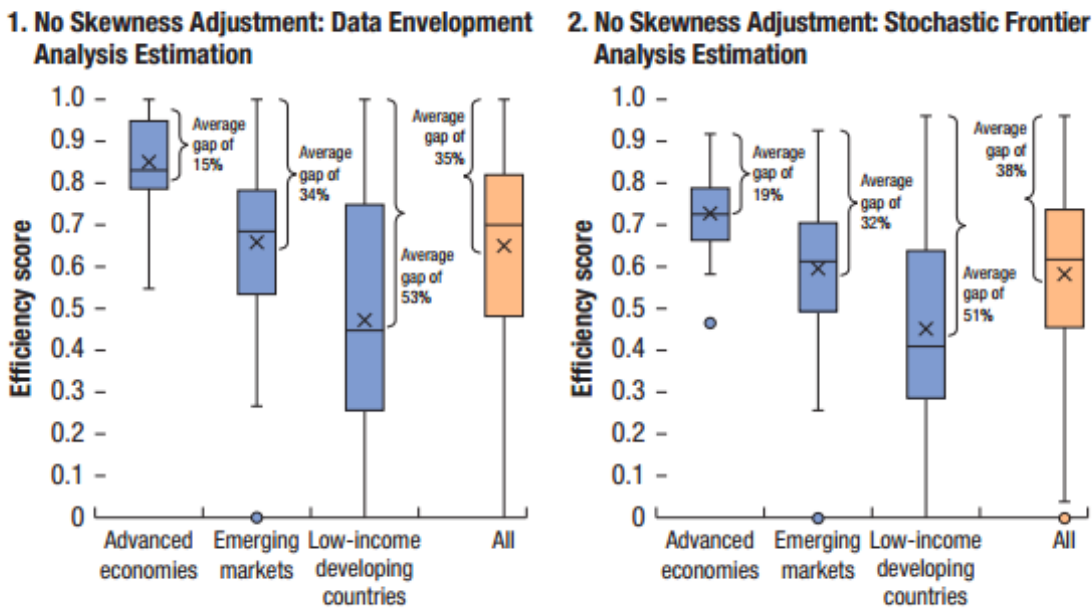

3. Skewness Adjustment: Data Envelopment Analysis Estimation

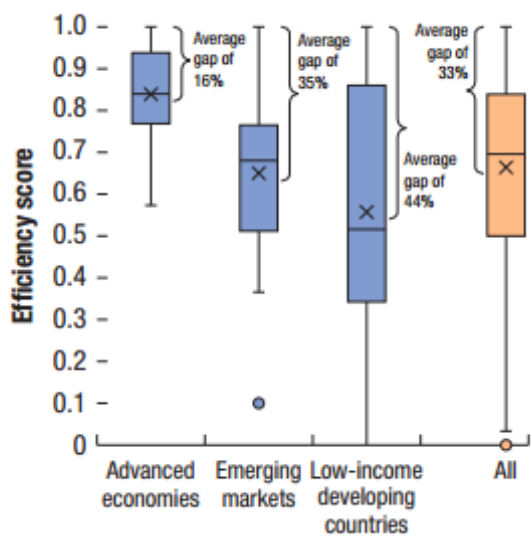

4. Skewness Adjustment: Stochastic Frontier Analysis Estimation

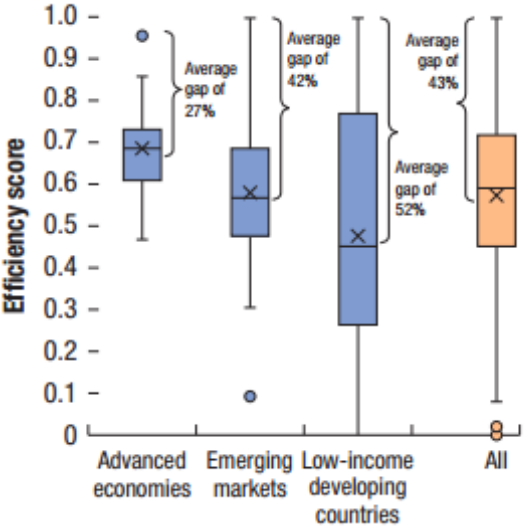

Figure 4 Public capital and infrastructure performance: hybrid public investment efficiency score by income level

Source: Anja Baum, Tewodaj Mogues, and Geneviève Verdier (2020) Getting the Most from Public Investment In: Schwartz, Gerd, Manal Fouad, Torben Hansen, and Geneviève Verdier, eds. 2020. Well Spent: How Strong Infrastructure Governance Can End Waste in Public Investment. Washington, DC: International Monetary Fund

Note: Each box shows the median and the 25th and 75th percentiles, and the whiskers show the nonlinear maximum and minimum values. Scores range between 0 and 1 . The average efficiency gap is computed as the mean percentage difference between the highest and the average efficiency scores. The four panels reflect different combinations of two aspects in the efficiency score derivation methodology.

Efficiency varies widely across income groups and regions. In general, the size of the gap shrinks as income rises. For example, as shown in Figure 4, panel 1 (data envelopment analysis, non-adjusted efficiency scores), on average, low-income developing countries face an efficiency gap of 53 percent, while emerging markets have a gap of 34 percent, and advanced economies a gap of 15 percent. The range between top and bottom performers declines as income rises. Inefficiencies in public investment spending are therefore substantial. This is a non-negligible source of wasted resources when needs are high and fiscal space is limited, as in the midst of lockdowns. Better infrastructure governance would raise the efficiency of public investment spending and improve infrastructure outcomes. Adopting the public investment practices of best performers could help countries to close about half their efficiency gap.

In this situation, it becomes obvious that, all other things being equal, the adequate use of formal institutions in the hands of the state can give quite tangible economic effect. It is about the professionalism of the state in context of adequate institutionalization of the conditions for the implementation of infrastructure PPP projects, excluding corruption of the top power, reducing the area of shadow business, minimizing socio-economic inequality of citizens and aimed at understanding the value orientations of citizens doomed to poverty due to COVID-19. In other words, in the context of the coronavirus pandemic, the state should direct formal institutions, first of all, when implementing capital-intensive socially significant infrastructure PPPs, to create an adequate the more 
inclusive societal environment. This will reduce the area of distribution of informal institutions that provide irrational antisocial behavior of economic agents. Only this will allow the state to regain the confidence (trust) of citizens, to cooperate joint efforts to reopen the economy in the context of the coronavirus pandemic.

Policymakers should realize epinomic strategies taking into account the following: to choose how to invest for the future in a fiscally prudent way, to adopt well-planned discretionary policies to stimulate demand, and to enhance social safety nets and unemployment benefits [Gaspar, et al., (2020)]. It is choosing an adequate form of PPP organization for implementing socially significant projects in the infrastructure according to dimensions of sustainable infrastructure and other UN SDG. Dealing with all the basic types of PPP organization: quasi-market, hierarchical and hybrid, as well as all numerous variety of their mixed forms [forthcoming Vaslavskiy Y., et al. (2020). Institutional Matrices: Modelling of Organizational Forms of Public-Private Partnership]. Each individual basic type of PPP organization (its institutional matrix) contains many potential sub-options for its reproduction.

\section{CONCLUSION}

So, the solution to the problems of the economic crisis caused by COVID-19 largely depends on the effectiveness of the state, which directly depends on the restoration of interaction and mutual trust between the state and society. The latter is most feasible on the example of the accelerated development of PPPs in those areas of the state's activity that has been most affected by the COVID19 pandemic. It is about the sphere of public goods, which until COVID-19 were a priority area of partnership between the state and private business. After COVID-19, the state is forced to consider budgetary constraints and make informed choices among possible forms of "alliances" between the state and private investors. In this case, both the traditional goals of minimizing transaction costs and increasing the efficiency of transactions with public goods, and the time parameters for obtaining socially significant results should be taken into account. The basic forms of PPPs allow the state and private business to optimize the sharing of risks and the burden of expenses as the capabilities of the public segment expand, as well as in the process of creating optimal "rules of the game", conditions and effective incentives to maximize the potential of the national economy. The success of PPPs at the stage of economic revival after COVID-19 largely depends on how much the technology of attracting private investment to the implementation of capital-intensive long-term projects works, the state is not able to provide full budget financing for. Investments in infrastructure give a quick result in the economy recovering from the crisis, as jobs are immediately created in construction and industry, and employment growth helps support consumer demand. But most importantly, short-term increase in demand is followed by long-term multiplier effects. In order to achieve these goals everything should be done to create a trust driven recovery environment that is collaborative and partner and stakeholder friendly. National governments should review infrastructure PPP projects in the sectors most affected by the crisis - airports, ports, roads, transport, and energy - to understand demandand supply-side impacts. The primary problems that need to be resolved as soon as possible include obtaining an adequate assessment by states of the effectiveness of contractual provisions on PPP projects, expert consideration of restructuring and coordination of sources of contract financing, review of contracts and problem asset management tools [The World Bank FACTSHEET (2020)]. This should be done in discussion of the governments and their private partners and other relevant stakeholders such as financiers and regulators.

\section{REFERENCES}

[1] Bator, Francis M. (1960). The Question of Government Spending: Public Needs and Private Wants. New York: Harper and Brothers.

[2] Baxter David (2020) PPP and COVID-19 3rd CoWebinar April 29th pp. 1-3

[3] BCG. (2020). COVID-19: Win the Fight, Win the Future. Featured Insights. April

[4] Gjaja, Marin, Rich Hutchinson, Adam Farber, and Dan Kahn (2020). Three Paths to the Future. Boston Consulting Group. May 27

[5] Gaspar Vitor, Lam W. Raphael, Raissi Mehdi. (2020). Fiscal policies for the recovery from COVID-19 IMFBlog May 6 pp. 1-7

[6] IMF (2020). What is the COVID-19 crisis impact on public-private partnerships Public Financial Management Blog of IMF. April 30 pp. 1-5

[7] Mckinsey Global Institute (2020). Prioritizing Health: A Prescription for Prosperity. Executive summary. July

[8] Musgrave, Richard. (1959). The Theory of Public Finance. New York: McGrow-Hill.

[9] Pigou, Arthur. (1924). The Economics of Welfare. 2nd ed. London: McMillan

[10] Pranov B.M. Rassokhina T.V. (2019) Methodological approaches to the adaptation of the system of global indicators of achieving the goals in the field of sustainable development in the Russian Federation Modern Economy Success № 1 pp. 19-152

[11] Ritter, Gerhard. (1996). Storia dello Stato Sociale (Rome: Laterza). Translated from Der Sozialstaat 
Entstehung und Entwiklung im Internationalen Verleich (Munich: R. Oldenbourg Verlas, 1991)

[12] Tanzi, Vito, and Ludger Schuknecht. (2000). Public Spending in the 20th Century. Cambridge: Syndicate of the Press of the University of Cambridge.

[13] The World Bank FACTSHEET (2020). PPPs and COVID-19 resources April 9 pp. 1-10

[14] Vaslavskaya I.Yu. (2019). Public-private partnership and financing the development of national infrastructure: safeguarding public finance sustainability. In: Magdalena Ziolo (ed.). Social, Economic, and Environmental Impacts Between Sustainable Financial Systems and Financial Markets. USA, PA: IGI Global Publisher

[15] World Bank, (2017). Contribution of Institutional Investors. Private Investment in Infrastructure. 2011-H1 2017. World Bank Report. World Bank Group PublicPrivate Partnerships, Washington, DC: World Bank. 